\title{
Influence of Membrane Materials and Operational Modes on the Performance of Ultrafiltration Modules for Drinking Water Treatment
}

\author{
Gongduan Fan, Zhaoyue Su, Rujing Lin, Xiuyong Lin, Renxin Xu, and Wei Chen \\ College of Civil Engineering, Fuzhou University, Fuzhou, Fujian 350116, China \\ Correspondence should be addressed to Gongduan Fan; fgdfz@fzu.edu.cn
}

Received 24 December 2015; Revised 8 March 2016; Accepted 9 March 2016

Academic Editor: Atsushi Sudo

Copyright (c) 2016 Gongduan Fan et al. This is an open access article distributed under the Creative Commons Attribution License, which permits unrestricted use, distribution, and reproduction in any medium, provided the original work is properly cited.

\begin{abstract}
Polyethersulfone (PES), polyvinylidene fluoride (PVDF), and polyacrylonitrile (PAN) were prepared to purify micropolluted source water via a pilot-plant test. Integrative devices of in-line coagulation/ultrafiltration (UF) were proposed. Then the treatment performance, operation stability, clean methods, and fresh water recovery rate were assessed. The results showed that the membrane materials and operational modes did not result in significant difference of the removal efficiency of turbidity, $\mathrm{COD}_{\mathrm{Mn}}, \mathrm{and} \mathrm{NH}_{4}{ }^{-}$ $\mathrm{N}$. The uniform distribution porosity, better hydrophilicity, and higher thermal stability of the PES membrane made its specific flux (SF) more than double those of two other membranes; in addition, the transmembrane pressure (TMP) of PES membrane appeared to be the least influenced by temperature change. The hydrophilicity of UF membrane was not a conclusive factor with the critical flux. The inside-out module with higher fouling load presented higher decay rate of SF under fixed flux operation compared with outside-in modules in single filtration duration. The way of gas washing of outside-in modules as a supplement resulted in recovery improvement. The acid-base staggered method of inside-out module to carry out chemical enhanced backwash (CEB) can effectively intensify the effects of backwashing by water.
\end{abstract}

\section{Introduction}

Drinking water safety problem is still not optimistic in China at present $[1,2]$. With the development of industry and agriculture, and the improvement of the people's standard of living, pollution of industrial wastewater and domestic sewage has become more and more serious. Polluted water which carries huge amount of toxic and harmful substances is dispersed into the water body, causing ever-decreasing self-purification capacity of natural water. The restriction of conventional water treatment process in waterworks is becoming apparent [3]. Ultrafiltration (UF), as the third technology of purifying drinking water, is widely used in the field of drinking water treatment because of its peculiar advantage with the improvement in membrane quality and decrease in membrane costs $[4,5]$. UF has been reported to have the advantages of effectively removal of suspended matters, colloid, pathogenic microorganism and macromolecule organic matters [6], ease of operation, and small footprint
$[7,8]$. UF membranes materials can be divided into organic and inorganic materials; common commercial ones are organic polymer materials such as polyethersulfone (PES), polyvinylidene fluoride (PVDF), polyacrylonitrile (PAN), polysulfone (PS), and polyvinyl chloride (PVC) $[9,10]$. The performance of UF largely depends on the properties of membrane materials and operational modes. C. Jönsson and A.-S. Jönsson [11] indicated that the pore size and the hydrophilic/hydrophobic properties of the UF membrane material were correlated to the extent of the flux reduction. $\mathrm{Li}$ et al. [12] showed that improving hydrophilicity of the membrane could reduce membrane fouling in a certain extent and the improvement of membrane hydrophilicity and the increase of the efficient filtration area through modification resulted in better permeation performance. The permeations of thermally stable membranes were also found to have received significantly enhanced interest because of their advantage to increase permeate flux with an increasing operating temperature compared to the common membranes 
TABLE 1: Membranes characteristics and operation parameters of the UF modules.

\begin{tabular}{|c|c|c|c|}
\hline Items & Module A & Module B & Module C \\
\hline Membrane material & PES & PVDF & PAN \\
\hline Operation mode & Inside-out & Outside-in & Outside-in \\
\hline Filtration mode & Dead-end & Dead-end & Dead-end \\
\hline Membrane effective area, $\mathrm{m}^{2}$ & 55 & 77 & 45 \\
\hline Average pore size, $\mathrm{nm}$ & 20 & 30 & 50 \\
\hline Contact angle & 44 & 66 & 52 \\
\hline Restorative flush mode & $\mathrm{BW}+\mathrm{FF}$ & $\mathrm{Air}+\mathrm{BW}+\mathrm{FF}$ & Air + BW \\
\hline Filtration duration, $\min$ & 40 & 30 & 30 \\
\hline Designed permeate flux, LMH & $60 \sim 120$ & $50 \sim 80$ & $44 \sim 66$ \\
\hline Feed pressure, $\mathrm{MPa}$ & $0.1 \sim 0.3$ & $<0.6$ & $<0.15$ \\
\hline TMP, MPa & $0.01 \sim 0.10$ & $<0.15$ & $<0.08$ \\
\hline Chemical of CEB & $\mathrm{HCl} /(\mathrm{NaClO}+\mathrm{NaOH})$ & $\mathrm{NaClO}+\mathrm{NaOH}$ & $\mathrm{NaClO}+\mathrm{NaOH}$ \\
\hline Frequency of CEB, h & 24 & 24 & 24 \\
\hline
\end{tabular}

Air: air washing; FF: forward flushing; BW: backwashing

Dead-end: all of the feed solution (100\%) passes through the filter medium without concentrated water discharge.

which need to be operated using cooling systems [13]. What is more, the operational modes of UF can be sorted into insideout and outside-in UF modes [14]. Inside-out UF mode means that the separation layer is the inner surface of fibers and the feed water flows inside the fibers, while the outside-in UF mode means that separation layer is on the outside surface of the fiber and the feed water flows outside the fibers. The differences between operational modes of UF modules result in different suitable membrane materials, different washing methods, and different application conditions. The inside-out UF module needs to use materials with higher stiffness and good acid and caustic resistance, such as PES, for adapting its washing method of using the strong flow of water to flush and the acid-base staggered method to carry out chemical enhanced backwash (CEB); its poorer capacity of receiving pollutants makes the inside-out UF module match the field of drinking water treatment. The outside-in UF module needs to use materials with higher strength, such as PVDF and PAN, for adapting to the way of gas washing; its lower fouling load caused by larger flow channel extends its applications in water and wastewater treatment. Therefore, different membrane materials and operational modes will inevitably result in different adaptability in special condition of raw water quality. In this pilot study, three kinds of hollow fiber UF modules made by different materials and operated under different operational modes were chosen to purify micropolluted source water of Minjiang River, and in order to reduce the membrane fouling [15] and enhance removal of organics $[16,17]$, integrative devices of in-line coagulation/UF were proposed. Their treatment performance, operation stability, clean methods, and fresh water recovery rate were assessed. The objective of this paper is to evaluate the influence of different membrane materials and operational modes on the performance of UF modules for drinking water treatment.

\section{Materials and Methods}

2.1. Integrative Devices. Three types of hollow-fiber membranes which are widely used for drinking water production were used in this study; virgin PES, PVDF, and PAN were prepared to construct combined processes of in-line coagulation/UF. The main membranes characteristics and operation parameters of these three membrane systems are shown in Table 1 and the schematic diagram of the UF pilot testing systems is shown in Figure 1, respectively. The coagulant was added (at a concentration of $4 \mathrm{mg} / \mathrm{L}$ ) to raw water entering into the water plant from Minjiang River and rapidly mixed by the tubular static mixer and mechanical mixer in conventional coagulation and flocculation unit. The water was then pumped into the feed tank of three UF systems, respectively. In this pilot study, the inside-out hollow fiber UF membrane was made by PES (Module A), and two other outside-in hollow fiber UF membranes were made by PVDF (Module B) and PAN (Module C), respectively. Each UF system had its own filtration and restorative cleaning mode. The transmembrane pressure (TMP) and membrane permeate flux were continuously monitored by pressure gauges and electronic flowmeters, respectively. For each filtration and forward flushing procedure, water from the feed tank was pumped by feed pump to the module, and the permeate from the module overflowed its permeate tank and then was rejected back to the draining tank. For each backwash and CEB procedure, filtrate from the permeate tank was pumped by the backwashing pump to the module. The CEB was carried out every 24 hours for each module to eliminate microorganism and the pollutants that are hard to remove completely by backwashing.

2.2. Raw Water Quality. The pilot test was carried out in a water plant in Fuzhou Coastal Section of Minjiang River. For the water quality status of Minjiang River, it was seen that its water quality deteriorates rapidly in the past few years as discharge from factory effluent and domestic wastewater increase. On the other hand, for some selfreasons of some enterprises, such as the unadvanced equipment, mismanagement, and low technology level, emissions of pollutants cannot reach the national draining standard, which results in seasonal and unusual phenomena of the 


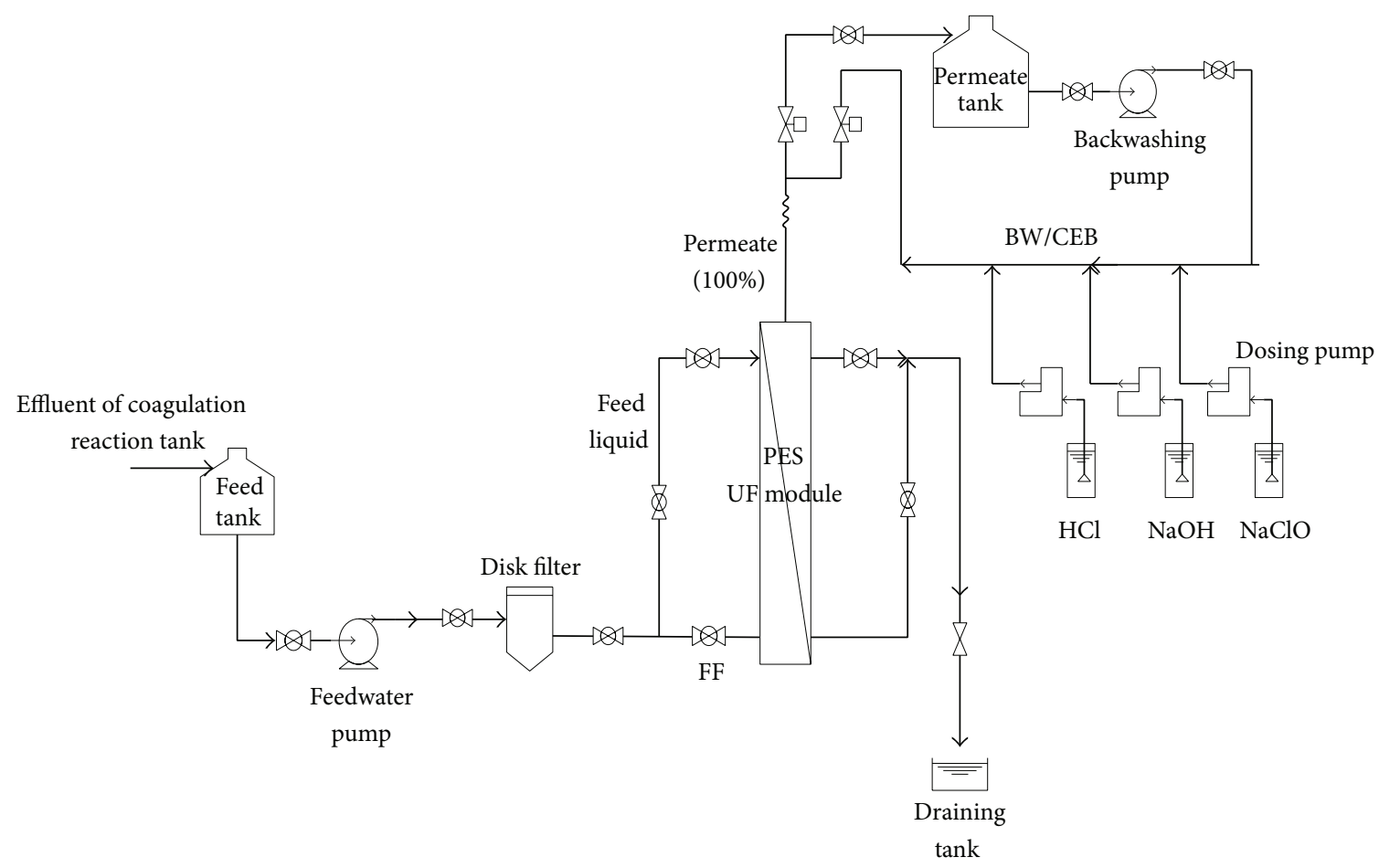

(a) The integrative device of in-line coagulation and inside-out hollow fiber UF modules

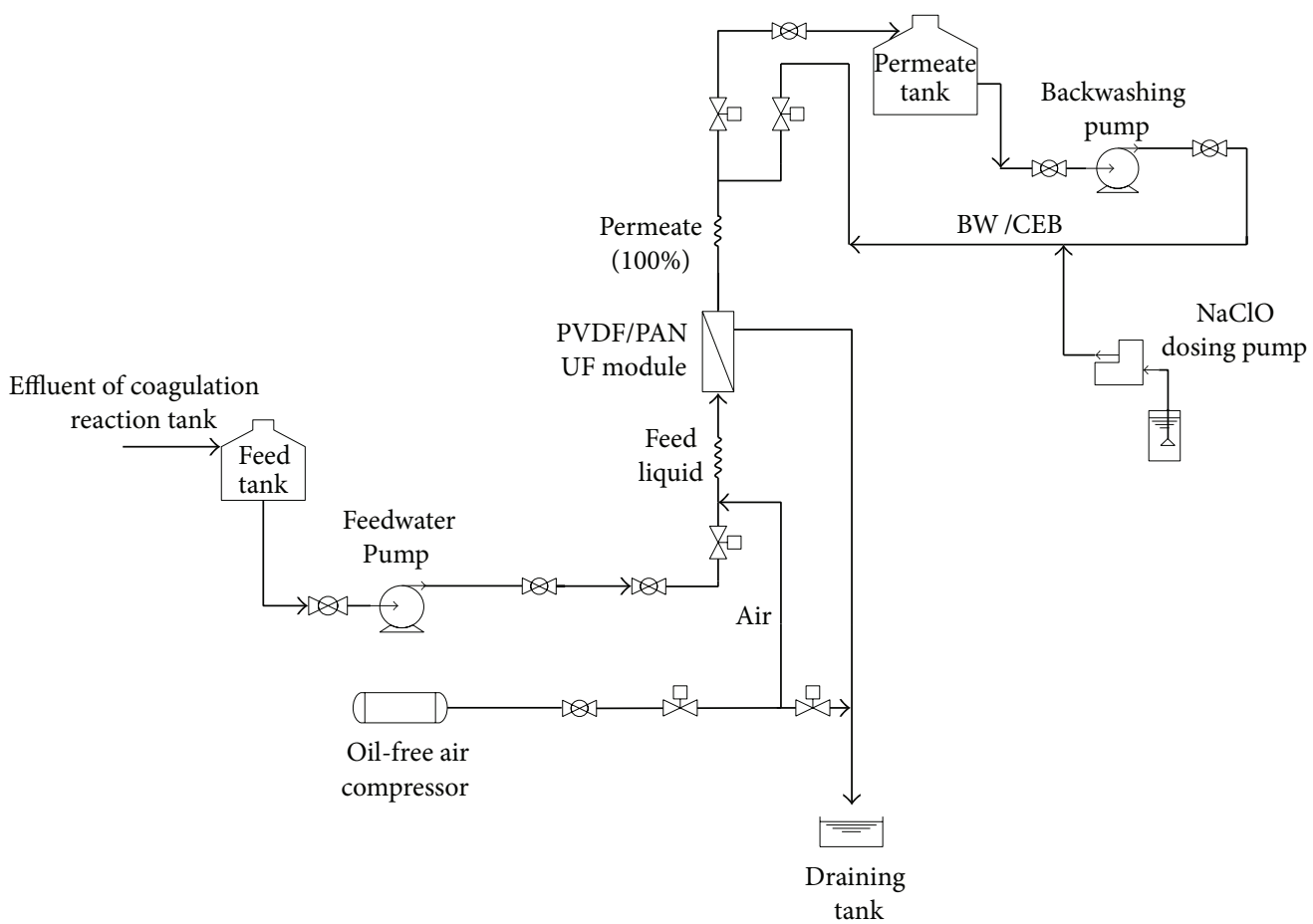

(b) The integrative device of in-line coagulation and outside-in hollow fiber UF modules

FIGURE 1: The schematic diagram of the three UF pilot testing systems.

water quality of Minjiang River. According to the statistics, turbidity, organic content, and ammonium nitrogen $\left(\mathrm{NH}_{4}{ }^{-}\right.$ $\mathrm{N})$ concentrations are abnormally high in late spring and early summer each year regularly; therefore, assessment of purifying effects of different models is based on these three water quality indexes in this study. Source water from the drinking water treatment plant in this pilot test had $\mathrm{pH}$ 6.80 7.66, turbidity $14.0 \sim 80.0 \mathrm{NTU}, \mathrm{COD}_{\mathrm{Mn}}$ value $1.80 \sim 5.13 \mathrm{mg} / \mathrm{L}$, and $\mathrm{NH}_{4}-\mathrm{N}$ concentration $0.08 \sim 0.68 \mathrm{mg} / \mathrm{L}$, respectively. 


\section{Results and Discussion}

3.1. Removal Abilities of Turbidity by Various UF Modules. The values of turbidity of permeate was measured during the long run in the pilot test, which is shown in Figure 2. The average turbidity of the permeation of PES, PVDF, and PAN module was 0.097, 0.109, and 0.101 NTU, respectively, and the average removal ratios of turbidity by these three modules were all higher than 99.5\%. Various UF modules did not result in significant difference of the effluent turbidity. Notably, each UF module could reduce the influent turbidity (7.2 54.6 NTU) which fluctuated drastically to about $0.1 \mathrm{NTU}$ steadily because of the powerful fractionation performance of the special tiny holes of UF membranes. It should be noted that an abnormal peak at $0.19 \mathrm{NTU}$ was found during the testing phase, which was due to the colored $\mathrm{NaClO}$ dissolved in the filtrate. Actually, a short while before filtrate sampling, the CEB process of PVDF module has just been completed, which was likely to result in $\mathrm{NaClO}$ residual problems on the pipeline system.

3.2. Removal Abilities of $\mathrm{COD}_{M n}$ by Various UF Modules. $\mathrm{COD}_{\mathrm{Mn}}$ value can be regarded as an index reflecting the content of organic substances in aqueous solution. The result from $\mathrm{COD}_{\mathrm{Mn}}$ measurements of the UF filtrate is presented in Figure 3. The average $\mathrm{COD}_{\mathrm{Mn}}$ concentration in the permeation of PES, PVDF, and PAN module was 1.37, 1.31, and $1.33 \mathrm{mg} / \mathrm{L}$, respectively. The average removal ratio of $\mathrm{COD}_{\mathrm{Mn}}$ by these three modules was $55.2 \%, 57.1 \%$, and $56.5 \%$, respectively, from which we can find that there was little difference between the three UF modules in removal capacity of $\mathrm{COD}_{\mathrm{Mn}}$. The coating layer which was formed on the membrane surface by flocs that hydrophobic macromolecular organic compounds had adsorbed on had an excellent retain capacity to micromolecular organics which can hardly be entrapped by UF membranes because of the relatively large pores of UF membranes [18], causing high removal efficiency of $\mathrm{COD}_{\mathrm{Mn}}$. Therefore, during the removal process, characteristics of membrane materials and the operational modes of the UF modules had little influence on the removal efficiency of organics. It can thus be seen that the removal ratio of $\mathrm{COD}_{\mathrm{Mn}}$ by the combined process of in-line coagulation and UF is only determined by raw water quality.

3.3. Removal Abilities of $\mathrm{NH}_{4}-\mathrm{N}$ Concentrations by Various UF Modules. The $\mathrm{NH}_{4}-\mathrm{N}$ concentration of UF influent and effluent during operation is shown in Figure 4. The average water $\mathrm{NH}_{4}-\mathrm{N}$ concentration from the permeation of PES, PVDF, and PAN module was 0.102, 0.100, and $0.093 \mathrm{mg} / \mathrm{L}$, respectively, under the same influent quality. The $\mathrm{NH}_{4}$ $\mathrm{N}$ concentrations of the effluent of different UF modules were more or less the same, indicating that UF membrane materials and operational modes have no apparent influence on the removal rate of $\mathrm{NH}_{4}-\mathrm{N}$ concentration by the process. In general, we can also find that all effluent $\mathrm{NH}_{4}-\mathrm{N}$ concentrations measured in this pilot test regardless of UF modules or influent quality were almost the same. In fact, UF membranes no matter which operational modes they

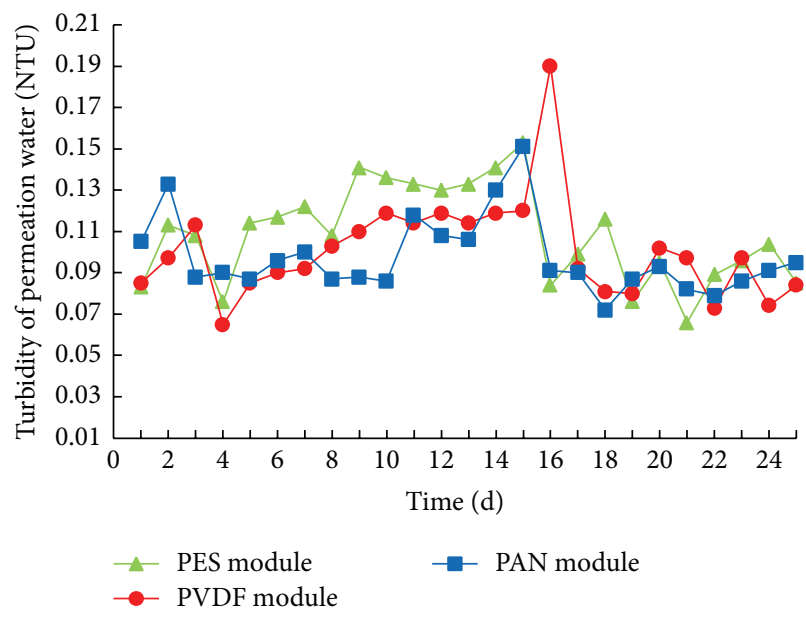

FIGURE 2: Turbidity trend of UF filtrate during the test period.

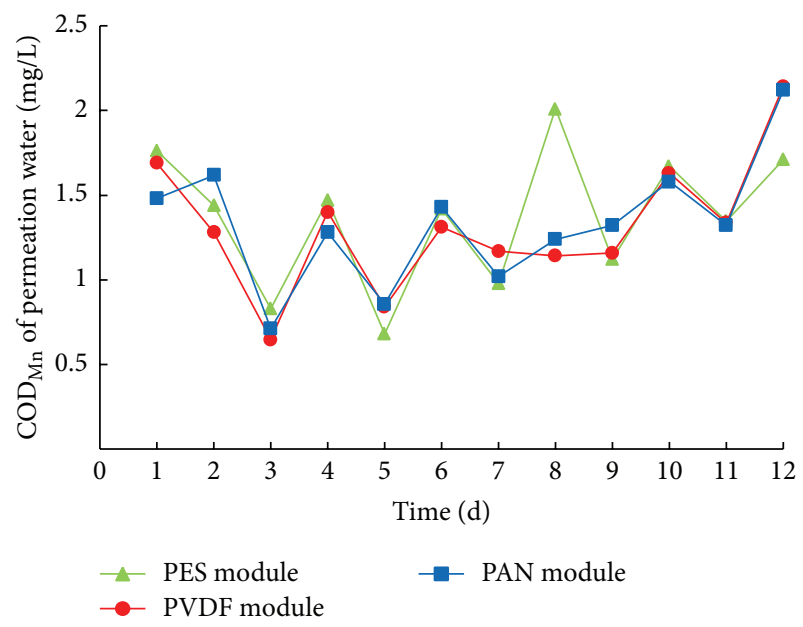

FIGURE 3: $\mathrm{COD}_{\mathrm{Mn}}$ trend of UF filtrate during the test period.

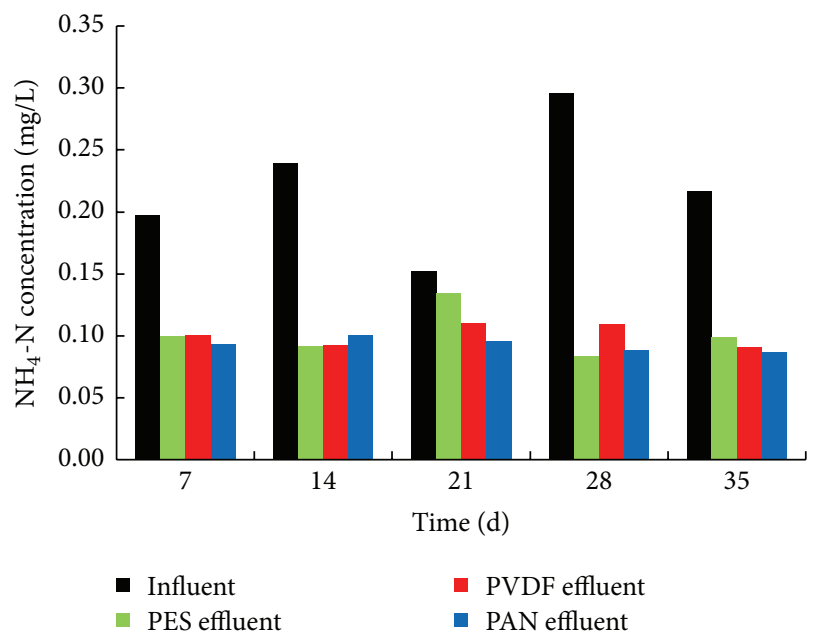

Figure 4: $\mathrm{NH}_{4}-\mathrm{N}$ concentration trend of UF filtrate during the test period. 


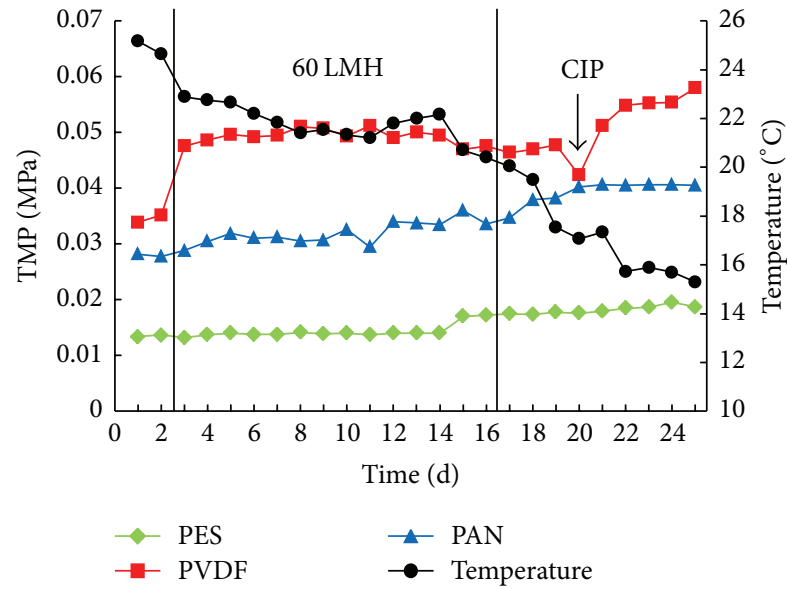

(a) TMP trend of UF modules and pilot test temperature

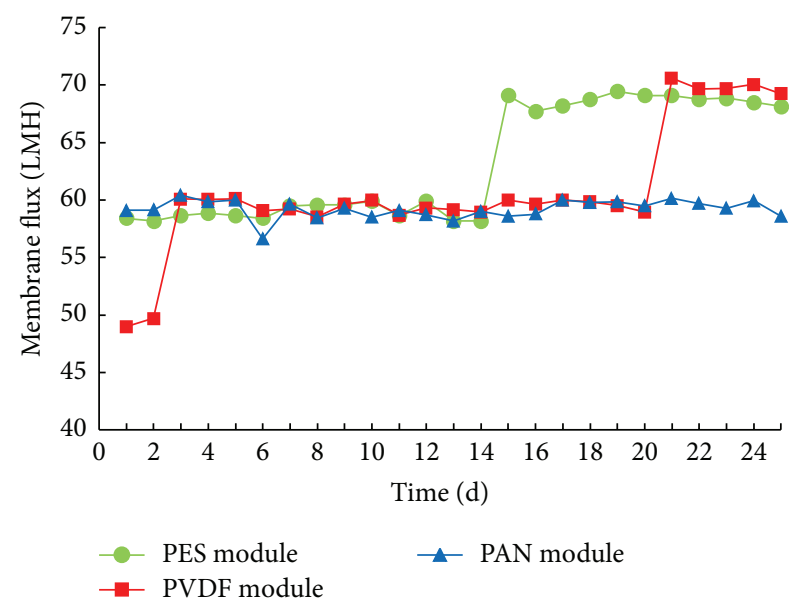

(b) Membranes flux adjustment of UF modules

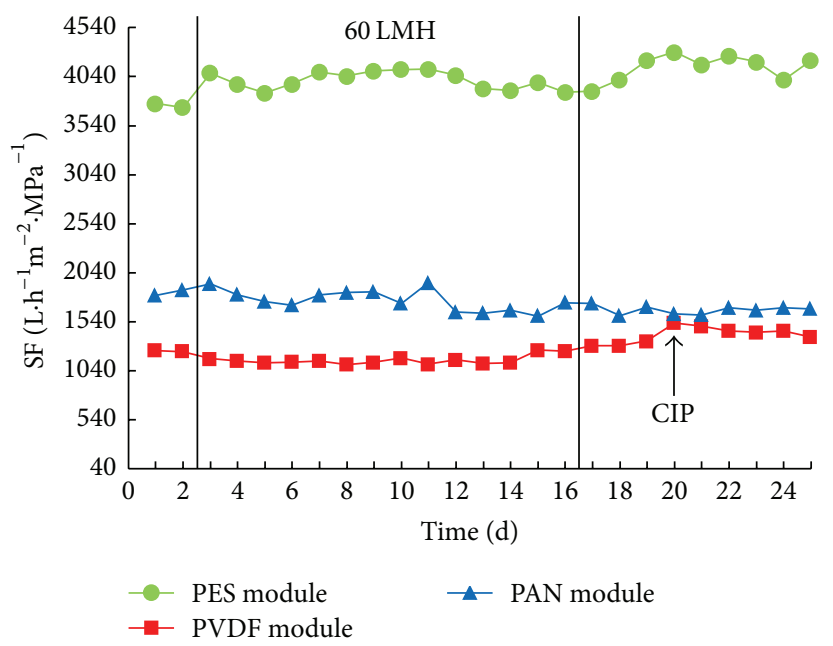

(c) Variation of SF of UF modules

FIGURE 5: Tendency of basic parameters of UF modules during runtime.

were operated on or which material they were made from, limited by the pore size, are not able to retain $\mathrm{NH}_{4}-\mathrm{N}$ which is in the form of ammonium salt $\left(\mathrm{NH}_{4}{ }^{+}\right)$and free ammonia $\left(\mathrm{NH}_{3}\right)$ in water [19]; only when UF combined with other process, such as oxidation, adsorption, or biological process, can $\mathrm{NH}_{4}-\mathrm{N}$ removal be effectively accomplished [20]. In this pilot test, a fairly small amount of $\mathrm{NH}_{4}-\mathrm{N}$ attached to suspensions and colloid substances and then was entrapped by UF membranes, thus proving the ability of $\mathrm{NH}_{4}-\mathrm{N}$ removal to some extent, during this process. It must be pointed out that the removal of high concentration $\mathrm{NH}_{4}-\mathrm{N}$ by the combined process of in-line coagulation/UF is poor, and process improvement should be conducted if necessary.

3.4. TMP, Membrane Permeate Flux, and Specific Flux (SF) Trends of Various UF Modules. The basic parameters which are shown in Figure 5, such as TMP, membrane permeate flux, and SF (corrected for temperature of the liquid), were monitored during the testing period. SF (also called permeability) which reflects the membrane resistance can be calculated according to the following equations:

$$
\mathrm{SF}=\frac{\mathrm{Q}}{A \cdot \mathrm{TMP} \cdot \mathrm{TCF}}, \mathrm{L} \cdot \mathrm{h}^{-1} \cdot \mathrm{m}^{-2} \cdot \mathrm{MPa}^{-1}(\mathrm{LMH}),
$$

TCF

$$
=\frac{1855-5596 \cdot 10^{-2} \cdot T_{\text {reference }}+6533 \cdot 10^{-4} \cdot T_{\text {reference }}^{2}}{1855-5596 \cdot 10^{-2} \cdot T_{\text {measured }}+6533 \cdot 10^{-4} \cdot T_{\text {measured }}^{2}},
$$

where $Q$ is permeate flow rate of UF membrane, $A$ is the membrane area, TCF is the temperature calibration factor, $T_{\text {reference }}$ is the reference temperature $\left(20^{\circ} \mathrm{C}\right)$, and $T_{\text {measured }}$ is the measured temperature in the pilot test, respectively.

As shown in Figure 5(c), SF trends of PES and PVDF modules remained stable during continuous, synchronous, and fixed flux operation, while SF of PAN membrane presented obvious downtrend, which indicated that the pollution degree of the PAN membrane was greater than that of PES 
and PVDF membranes. As can be seen from Figure 5(a), when these modules were operated at flux of $60 \mathrm{LMH}$, the TMP of PAN module showed the most obviously ascending trend with the decrease of temperature, while PVDF and PES modules were relatively stable, and the increase of TMP of PVDF membrane was somewhat greater than that of PES. Actually, the TMP of UF membranes was enhanced in inverse proportion to the operating temperature for the reason that the activity of the solute in the mixture of feed solution had a tendency to increase but the viscosity of the feed solution decreased as the temperature increased [21, 22]. Furthermore, the increase of TMP during the running process of the system not only was caused by the descent of temperature, but also was associated with the increased intensity of membrane fouling. In conjunction with Figure 5(c), we can see that, after being corrected for temperature, SF of PAN module did not keep stable like PES and PVDF modules but presented a downward tendency to some extent. Therefore, we have every reason to believe that the increase of TMP of PAN module was mainly due to membrane fouling, while the slight increase of TMP of PVDF membrane was caused by the decrease of temperature. From the view of membrane material, it is worth noticing that the well-distributed pore size, better hydrophilicity, and higher thermal stability of the PES membrane made its SF more than double those of the other two membranes and the TMP of PES module appeared the least influenced by temperature. In fact, according to measurement results of contact angle from Table 1, the hydrophilicity of PES was the strongest, the second was PAN, and PVDF was the weakest in this pilot test $[19,20]$. In addition, the fine and uniformity pores of PES membrane lead to higher adaptability in the drinking water treatment of which the demand of raw water quality and effluent water quality are relatively high.

Before the process of CIP (clean in place) in PVDF module which was operated at flux of $60 \mathrm{LMH}$, we noticed that the SF of PVDF and PES modules which was operated in synchronization and under the same flux remained stable. However, when membrane flux of PVDF module was changed to $70 \mathrm{LMH}$ after CIP, with the running time growth, SF of PVDF presented obvious downtrend compared to PES module operated at flux of $70 \mathrm{LMH}$, which indicated that the flux of PVDF membrane had exceeded the critical point, called critical flux [23]. In fact, the better hydrophilicity and well-distributed pore size of PES membrane help lower TMP and operating pressure to some extent; therefore, the TMP of PES module was still far from design value, the SF has almost no attenuation in system running phase.

As shown in Figure 5(c), when these modules were operated at flux of $60 \mathrm{LMH}$, the SF of PES was the maximum one, the second was PAN, and PVDF was the minimum in this pilot test. It can be seen that the SF was consistent with the hydrophilicity of UF membranes. For PAN and PVDF modules, as the outside-in UF modules, the decreasing rate of permeability of the former was larger than that of the latter, which indicated that the hydrophilicity was not conclusive factor with the critical flux.

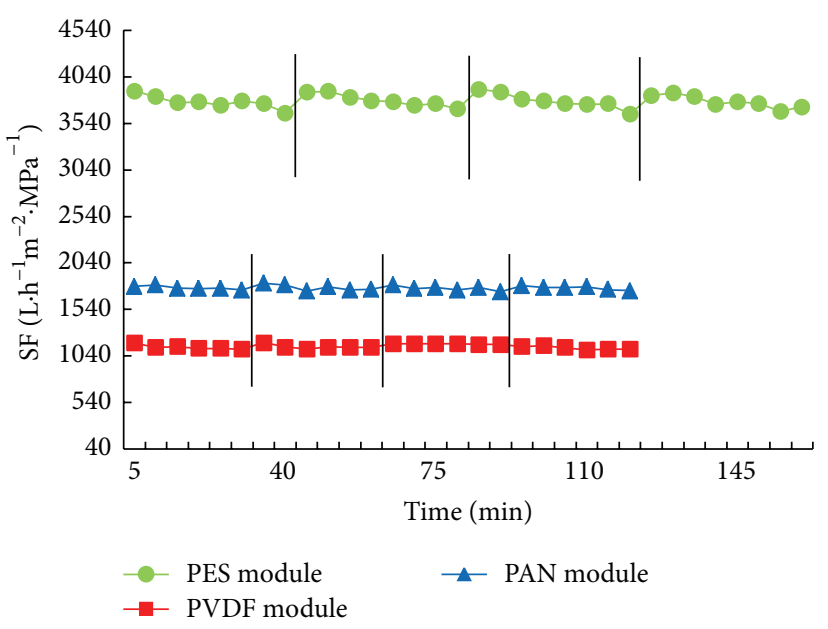

FIGURE 6: SF trends of various UF modules in four filtration durations.

3.5. SF Trends of Various UF Modules in Single Filtration Duration. Figure 6 shows the SF of these three UF modules operated at flux of $60 \mathrm{LMH}$ in four filtration durations. The data of SF were recorded every five-minute interval. The decay rate of SF of PES, PVDF, and PAN modules was $81.65,44.56$, and $49.74 \mathrm{~L} \cdot \mathrm{h}^{-1} \cdot \mathrm{m}^{-5} \cdot \mathrm{MPa}^{-1}$, respectively. As shown in Figure 7, the flow channel of the capillary inside-out UF module (PES module) is much smaller than outside-in UF module (PVDF and PAN modules), which resulted in poorer capacity of receiving pollutants. With the extension of operating time and increase of the amount of the contaminant attaching onto the membrane surface, insideout module with higher fouling load presented higher decay rate of SF under fixed flux operation compared with outsidein modules in single filtration duration. The permeability of these three modules can be resumed to the initial filter competence through their own restorative flush mode, but some particulate fouling was still present after hydraulic clean $[24,25]$, which resulted in the decay of permeability of PAN module in the overall system operation process. Moreover, the pretreatment of inside-out module should be noted according to raw water quality due to its poorer dint capacity.

3.6. Comparison of the Washing Methods of Membranes. Each UF module has its own washing methods whose appropriateness mainly depends upon their operational modes. In this pilot study, the washing methods of these three UF modules proved to be effective. The outside-in UF module made by PVDF or PAN had backwashing "dead angles" because of the interspaces of membrane silk; in view of this problem, the use of a strong flow of water to backwash is not a good choice for the reason that the backwashing channel is much smaller than that of the inside-out UF module, as shown in Figure 7(c), resulting in strength problem for backwashing with large pressure and current. Therefore, the way of gas washing is chosen to be a supplement to backwashing by relatively small water flow, causing the improvement of the water production rate and increase of the power consumption to some extent. 


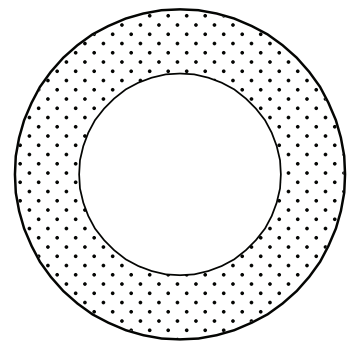

a) Hollow fiber membrane silk
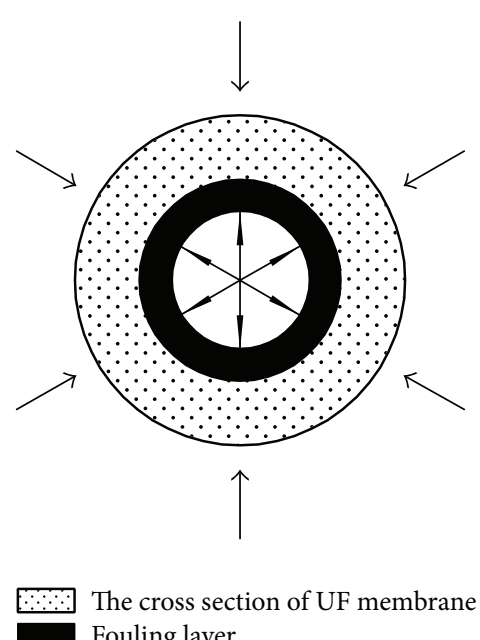
Fouling layer

(b) PES module

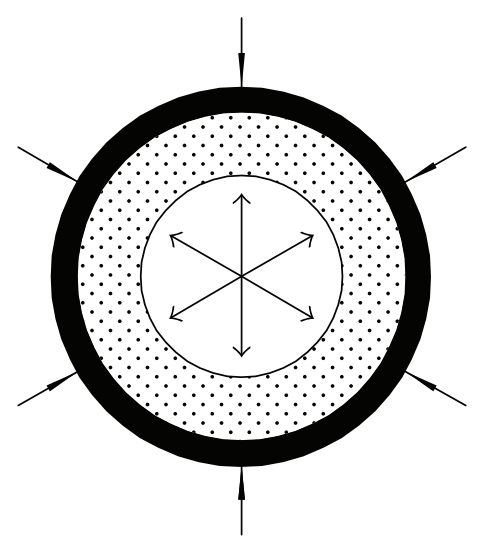

$\longrightarrow$ The direction of filtration
$\longrightarrow$ The direction of backwash

(c) PVDF/PAN module

FIGURE 7: Flow channel of various UF modules.

Operational experience has shown that air-water washing is suitable for flux recovery of outside-in UF modules. The recovery of PES, PVDF, and PAN modules operated at flux of $60 \mathrm{LMH}$ was $93.5 \%, 95.3 \%$, and $95.9 \%$, respectively, and the product water recovery of the former was lower than that of the latter two by $1 \%$. It is worth noticing that there is no question of the so-called backwashing "dead angles" of inside-out module for the reason that the voids between its membranes silks were filled with filtered water instead of the accumulation of pollutants solids, compared to outside-in modules. As shown in Figure 7(b), the backwashing channel of inside-out module was large enough to withstand water backwashing with large pressure and current; therefore, it would require no gas washing and also would not fit to gas washing because of certain restrictions on the physical strength of the membrane, which reduced energy consuming and recovery rate of water production. It should be noted that acid and alkaline resistance of inside-out membrane made by PES is appropriate for the acid-base staggered method to $\mathrm{CEB}$, which can intensify the effects of backwashing by water through inorganic and organic foulants cleaning [26] and therefore replace the way of gas washing of the outsidein UF module made by PVDF and PAN to some extent. In that sense, the selection of membrane material is dependent on the operational mode of UF module in a certain degree.

\section{Conclusions}

The water purification effect of UF modules made by PES, PVDF, and PAN was equivalent. PES module presented outstanding advantages for higher permeability and lower energy consuming because of the better hydrophilicity, uniform distribution porosity, and higher thermal stability of PES membrane. However, due to the higher fouling load caused by the smaller flow channel compared to outsidein module (PAN and PVDF modules), the pretreatment of inside-out module (PES module) should be noted according to raw water quality. The decreasing rate of permeability of PAN module was larger than that of PVDF module, indicating that the hydrophilicity was not conclusive factor with the critical flux. A strong flow of water to flush and the acid-base staggered method to CEB of the inside-out module increased the chemicals consumption and makes the product water recovery lower than that of outsidein modules by $1 \%$, while air-water washing is suitable for flux recovery of outside-in UF modules, resulting in the improvement of the water production rate and the increase of the power consumption. The selection of membrane material is dependent on the operational mode of UF module to some extent.

\section{Competing Interests}

The authors declare that there is no conflict of interests regarding the publication of this paper.

\section{Acknowledgments}

This work was supported by the National Natural Science Foundation of China (no. 51308123), China Postdoctoral Science Foundation (2014M561856), Housing and UrbanRural Development of Fujian (2014-K-05), and Opening Measuring Fund of Large Precious Apparatus of Fuzhou University (2016T041).

\section{References}

[1] J. Qu and M. Fan, "The current state of water quality and technology development for water pollution control in China," Critical Reviews in Environmental Science and Technology, vol. 40, no. 6, pp. 519-560, 2010.

[2] X. Zhang, Q. Guo, X. Shen, S. Yu, and G. Qiu, "Water quality, agriculture and food safety in China: current situation, trends, 
interdependencies, and management," Journal of Integrative Agriculture, vol. 14, no. 11, pp. 2365-2379, 2015.

[3] R. Li, L. Zhang, and P. Wang, "Rational design of nanomaterials for water treatment," Nanoscale, vol. 7, no. 41, pp. 17167-17194, 2015.

[4] V. Discart, M. R. Bilad, S. Van Nevel, N. Boon, J. Cromphout, and I. F. J. Vankelecom, "Role of transparent exopolymer particles on membrane fouling in a full-scale ultrafiltration plant: feed parameter analysis and membrane autopsy," Bioresource Technology, vol. 173, pp. 67-74, 2014.

[5] M. Yao, J. Nan, Q. Li et al., "Effect of under-dosing coagulant on coagulation-ultrafiltration process for treatment of humic-rich water with divalent calcium ion," Journal of Membrane Science, vol. 495, Article ID 13888, pp. 37-47, 2015.

[6] X. Du, F. Qu, H. Liang et al., "Removal of antimony (III) from polluted surface water using a hybrid coagulation-flocculationultrafiltration (CF-UF) process," Chemical Engineering Journal, vol. 254, pp. 293-301, 2014.

[7] K. Kimura, Y. Hane, Y. Watanabe, G. Amy, and N. Ohkuma, "Irreversible membrane fouling during ultrafiltration of surface water," Water Research, vol. 38, no. 14-15, pp. 3431-3441, 2004.

[8] E. Zuriaga-Agustí, E. Alventosa-deLara, S. Barredo-Damas, M. I. Alcaina-Miranda, M. I. Iborra-Clar, and J. A. MendozaRoca, "Performance of ceramic ultrafiltration membranes and fouling behavior of a dye-polysaccharide binary system," Water Research, vol. 54, pp. 199-210, 2014.

[9] A. L. Ahmad, A. A. Abdulkarim, B. S. Ooi, and S. Ismail, "Recent development in additives modifications of polyethersulfone membrane for flux enhancement," Chemical Engineering Journal, vol. 223, pp. 246-267, 2013.

[10] J. Gu, Y. Bai, L. Zhang et al., "VTOS cross-linked PDMS membranes for recovery of ethanol from aqueous solution by pervaporation," International Journal of Polymer Science, vol. 2013, Article ID 529474, 7 pages, 2013.

[11] C. Jönsson and A.-S. Jönsson, "Influence of the membrane material on the adsorptive fouling of ultrafiltration membranes," Journal of Membrane Science, vol. 108, no. 1-2, pp. 79-87, 1995.

[12] Y. S. Li, L. Yan, C. B. Xiang, and L. J. Hong, "Treatment of oily wastewater by organic-inorganic composite tubular ultrafiltration (UF) membranes," Desalination, vol. 196, no. 1-3, pp. 76-83, 2006.

[13] J.-Y. Jeon, "Permeation properties of thermo-chemically stable ultrafiltration membranes of copoly(bis[4-(3-aminophenoxy) phenyl] sulfone/3,3',4,4'-benzophenonetetracarboxyl/pyromellite) imides," Desalination, vol. 296, pp. 46-52, 2012.

[14] J. Xu, G. Ruan, X. Gao, X. Pan, B. Su, and C. Gao, "Pilot study of inside-out and outside-in hollow fiber UF modules as direct pretreatment of seawater at low temperature for reverse osmosis," Desalination, vol. 219, no. 1-3, pp. 179-189, 2008.

[15] E. Barbot, S. Moustier, J. Y. Bottero, and P. Moulin, "Coagulation and ultrafiltration: understanding of the key parameters of the hybrid process," Journal of Membrane Science, vol. 325, no. 2, pp. 520-527, 2008.

[16] M. Kabsch-Korbutowicz, "Impact of pre-coagulation on ultrafiltration process performance," Desalination, vol. 194, no. 1-3, pp. 232-238, 2006.

[17] C. Guigui, J. C. Rouch, L. Durand-Bourlier, V. Bonnelye, and P. Aptel, "Impact of coagulation conditions on the inline coagulation/UF process for drinking water production," Desalination, vol. 147, no. 1-3, pp. 95-100, 2002.
[18] P.-K. Park, C.-H. Lee, S.-J. Choi, K.-H. Choo, S.-H. Kim, and C.H. Yoon, "Effect of the removal of DOMs on the performance of a coagulation-UF membrane system for drinking water production," Desalination, vol. 145, no. 1-3, pp. 237-245, 2002.

[19] S. Montalvo, J. S. Martin, C. Huiliñir, L. Guerrero, and R. Borja, "Assessment of a UASB reactor with high ammonia concentrations: effect of zeolite addition on process performance," Process Biochemistry, vol. 49, no. 12, pp. 2220-2227, 2014.

[20] Y. Chen, Y. Tu, Y. Bai, M. Tang, W. Liu, and H. Wu, "Combined adsorption/ultrafiltration of secondary effluents using powdered zeolites," Chemical Engineering \& Technology, vol. 39, no. 2, pp. 285-292, 2016.

[21] Y. Su, X. G. Jian, S. H. Zhang, and C. Yan, "Preparation of novel PPES-B UF membrane with good thermal stability: the effect of additives on membrane performance and cross-section morphology," Journal of Membrane Science, vol. 271, no. 1-2, pp. 205-214, 2006.

[22] J. Cai, E. Perfect, C.-L. Cheng, and X. Hu, "Generalized modeling of spontaneous imbibition based on hagen-poiseuille flow in tortuous capillaries with variably shaped apertures," Langmuir, vol. 30, no. 18, pp. 5142-5151, 2014.

[23] Y.-T. Chiou, M.-L. Hsieh, and H.-H. Yeh, "Effect of algal extracellular polymer substances on UF membrane fouling," Desalination, vol. 250, no. 2, pp. 648-652, 2010.

[24] Y. Bessiere, C. Guigui, P. J. Remize, and C. Cabassud, "Coupling air-assisted backwash and rinsing steps: a new way to improve ultrafiltration process operation for inside-out hollow fibre modules," Desalination, vol. 240, no. 1-3, pp. 71-77, 2009.

[25] P. J. Remize, C. Guigui, and C. Cabassud, "From a new method to consider backwash efficiency to the definition of remaining fouling," Desalination, vol. 199, no. 1-3, pp. 86-88, 2006.

[26] Y. C. Woo, J. J. Lee, L. D. Tijing, H. K. Shon, M. Yao, and H.S. Kim, "Characteristics of membrane fouling by consecutive chemical cleaning in pressurized ultrafiltration as pre-treatment of seawater desalination," Desalination, vol. 369, pp. 51-61, 2015. 

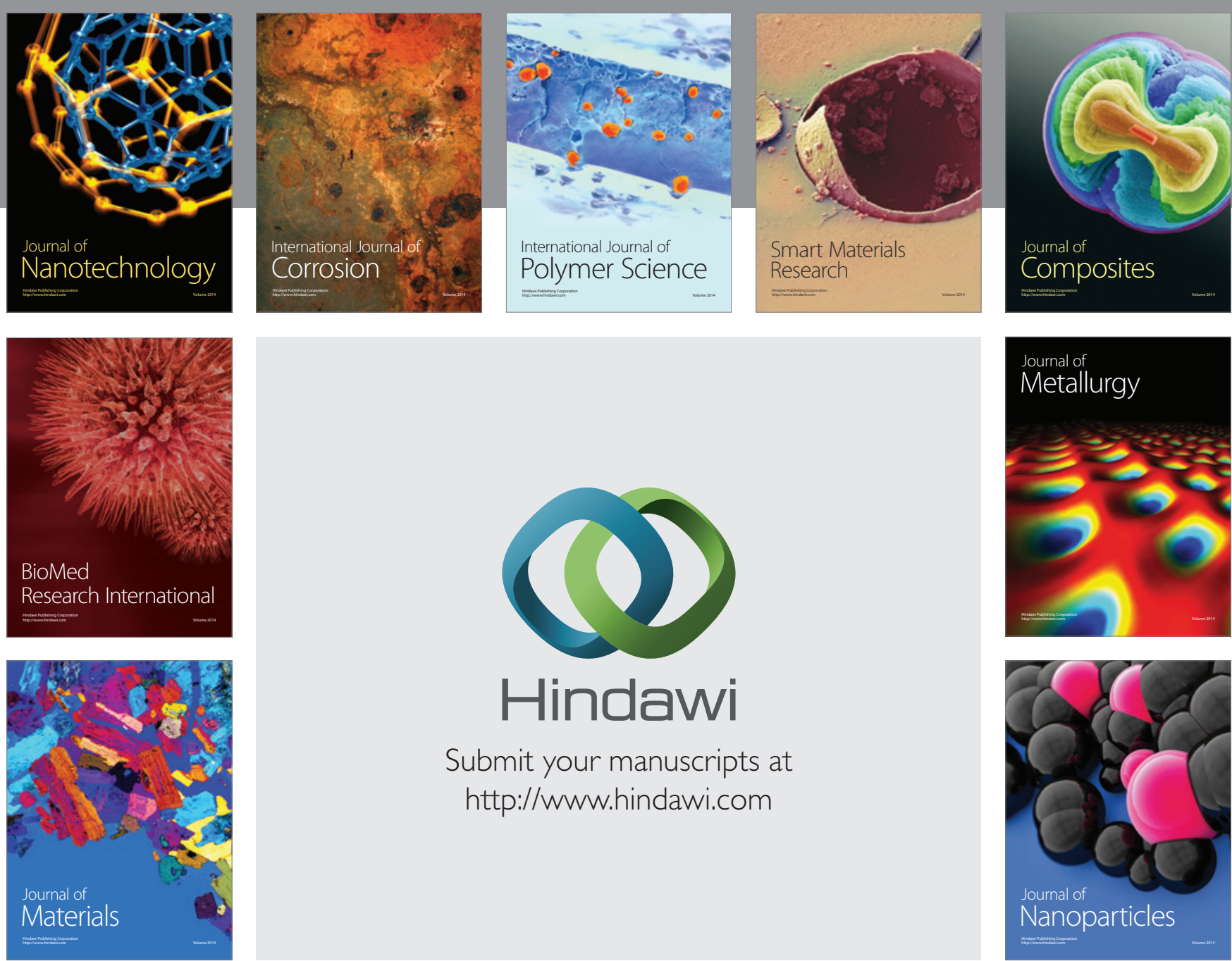

\section{Hindawi}

Submit your manuscripts at

http://www.hindawi.com

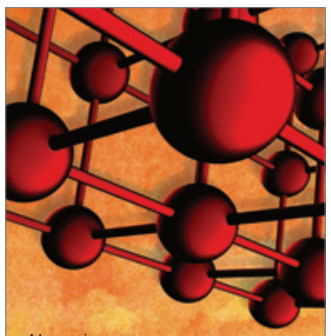

Materials Science and Engineering
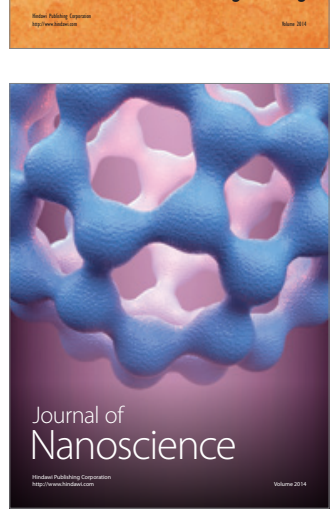
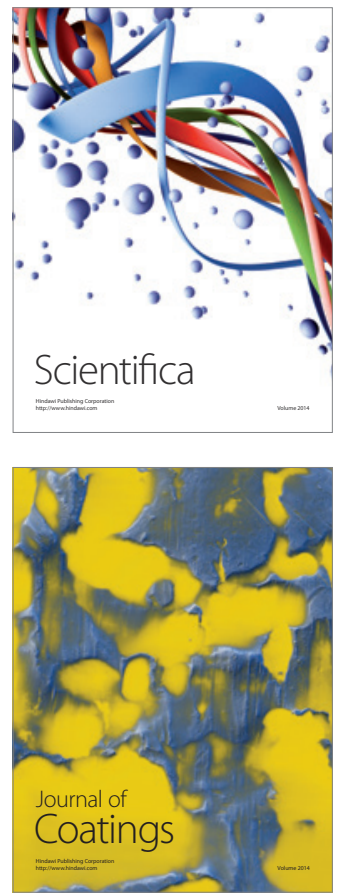
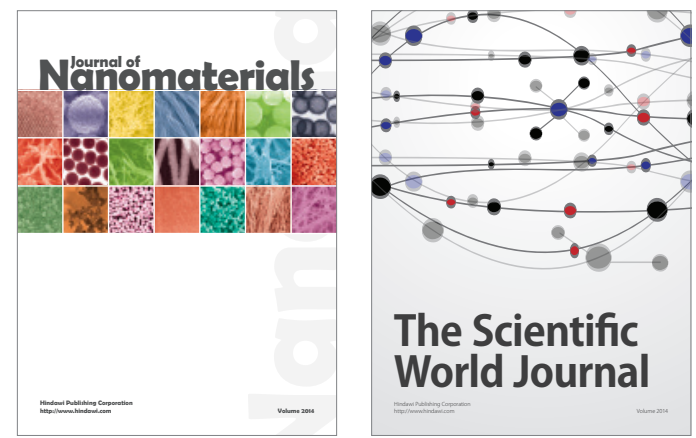

The Scientific World Journal
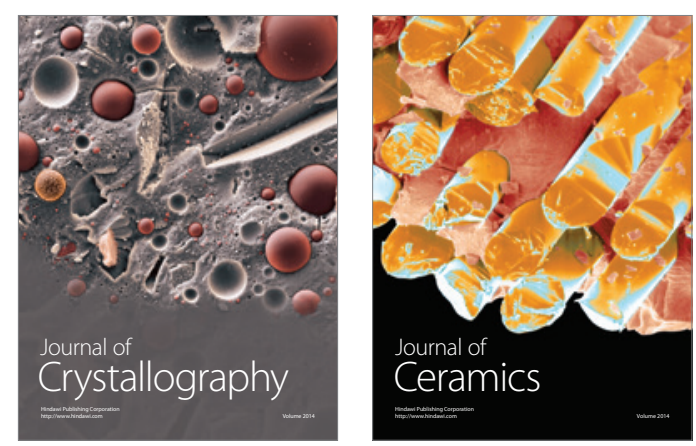
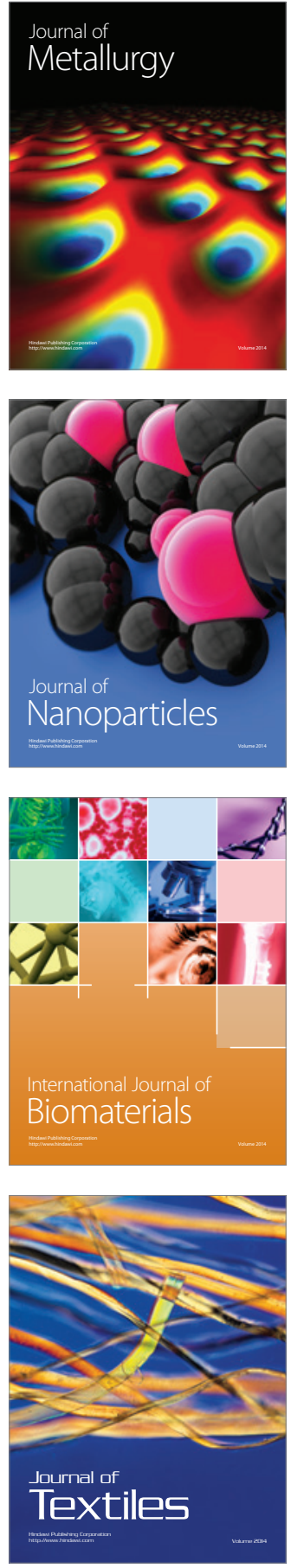